\title{
Donor surfactant protein A2 polymorphism and lung transplant survival
}

\author{
Frank D'Ovidio (1) ${ }^{1}$, Joanna Floros ${ }^{2}$, Beatrice Aramini ${ }^{1}$, David Lederer (1) ${ }^{1}$, \\ Susan L. DiAngelo ${ }^{2}$, Selim Arcasoy ${ }^{1}$, Joshua R. Sonett ${ }^{1}$, Hillary Robbins ${ }^{1}$, \\ Lory Shah ${ }^{1}$, Joseph Costa $^{1}$ and Andreacarola Urso ${ }^{1}$
}

Affiliations: 'Division of Thoracic Surgery, Lung Transplant Program, Columbia University Medical Center, New York, NY, USA. ${ }^{2}$ Center for Host Defense, Inflammation, and Lung Disease (CHILD) Research Department of Pediatrics, The Pennsylvania State University College of Medicine, Hershey, PA, USA.

Correspondence: Frank D'Ovidio, Surgical Director Lung Transplant Program, New York-Presbyterian Hospital, 161 Fort Washington Ave, New York, NY 10032, USA. E-mail: fd2133Acumc.columbia.edu

@ERSpublications

Donor genetic polymorphisms of the lung-specific innate defence systems determine post-lung transplant recipient outcome http://bit.ly/2QNpX7Q

Cite this article as: D'Ovidio F, Floros J, Aramini B, et al. Donor surfactant protein A2 polymorphism and lung transplant survival. Eur Respir J 2020; 55: 1900618 [https://doi.org/10.1183/13993003.00618-2019].

\begin{abstract}
Purpose: Gene polymorphisms of surfactant proteins, key players in lung innate immunity, have been associated with various lung diseases. The aim of this study was to investigate the potential association between variations within the surfactant protein (SP)-A gene of the donor lung allograft and recipient post-transplant outcome.

Methods: Lung-transplant patients $(\mathrm{n}=192)$ were prospectively followed-up with pulmonary function tests, bronchoscopies with bronchoalveolar lavage and biopsies. Donor lungs were assayed for SP-A1 $\left(6 \mathrm{~A}^{\mathrm{n}}\right)$ and SP-A2 $\left(1 \mathrm{~A}^{\mathrm{n}}\right)$ gene polymorphism using the pyrosequencing method. Unadjusted and adjusted stratified Cox survival models are reported.

Results: SP-A1 and SP-A2 genotype frequency and lung transplant recipient and donor characteristics as well as cause of death are noted. Recipients were grouped per donor SP-A2 variants. Individuals that received lungs from donors with the SP-A2 $1 \mathrm{~A}^{0}(\mathrm{n}=102)$ versus $1 \mathrm{~A}^{1}$ variant $(\mathrm{n}=68)$ or SP-A2 genotype $1 \mathrm{~A}^{0} 1 \mathrm{~A}^{0} \quad(\mathrm{n}=54)$ versus $1 \mathrm{~A}^{0} \mathrm{~A}^{1} \quad(\mathrm{n}=38)$ had greater survival at 1 year (log-rank $\left.\mathrm{p}<0.025\right)$. No significant association was noted for SP-A1 variants. Stratified adjusted survival models for 1-year survival and diagnosis showed a reduced survival for $1 \mathrm{~A}^{1}$ variant and the $1 \mathrm{~A}^{0} 1 \mathrm{~A}^{1}$ genotype. Furthermore, when survival was conditional on 1-year survival no significance was observed, indicating that the survival difference was due to the first year's outcome associated with the $1 \mathrm{~A}^{1}$ variant.

Conclusion: Donor lung SP-A gene polymorphisms are associated with post-transplant clinical outcome. Lungs from donors with the SP-A2 variant $1 \mathrm{~A}^{1}$ had a reduced survival at 1 year. The observed donor genetic differences, via innate immunity relate to the post-transplant clinical outcome.
\end{abstract}




\section{Introduction}

Lung transplantation is a widely accepted therapeutic option for end-stage lung disease. Yet, clinical outcome is challenged by primary graft failure, responsible for the majority of the early mortality, and by chronic allograft dysfunction and chronic rejection accounting for $>30 \%$ of deaths after the third post-operative year. Lung transplantation suffers recipient and graft survival, significantly lower than for liver, kidney and heart transplantation. The lung's ongoing exposure to the environment is probably the determining factor, with a significant role attributed to the performance of its defence mechanisms.

Pulmonary surfactant and the surfactant-related proteins are primary components of the organ's specific innate immunity. As such, they serve as one of the first host defence mechanisms mounted by the lung against the various insults. In addition to lowering the alveolar surface tension, surfactant phospholipids serve as part of the physical mucosal barrier [1,2]. Similarly, surfactant associated proteins $\mathrm{A}, \mathrm{B}, \mathrm{C}$ and D play different specific roles with respect to surface tension lowering function, phospholipid homeostasis and innate and adaptive immunity [3-8]. The hydrophilic surfactant proteins (SP)-A and SP-D play essential roles in innate host defence, interacting between the innate and the adaptive immune systems [3-8].

SP-A biological activity seems to be genetically determined and its polymorphisms have been associated with several lung disease: respiratory distress syndrome, idiopathic pulmonary fibrosis and emphysema [9, 10]. The two sftpal and sftpa2 genes, encoding the proteins SP-A1 and SP-A2, respectively, have been identified with several polymorphisms within the coding regions, SP-A1 $\left(6 \mathrm{~A}, 6 \mathrm{~A}^{2-20}\right)$ and SP-A2 (1A, $\left.1 \mathrm{~A}^{0-13}\right)[11,12]$. In particular, SP-A2 is the predominant and very polymorphic SP-A protein present in the adult human airways [13].

We showed a differential SP-A protein expression in the peri-lung transplant phase according to the SP-A2 variants and further showed a significant pharmacogenetic relationship with of the SP-A2 methylprednisolone treatment $[14,15]$.

These observations allowed us to formulate the main hypothesis for this project which focuses on pulmonary SP-A2 polymorphisms determining lung allograft survival.

\section{Methods}

The study was approved by the institutional review board of the Columbia University Medical Center (New York, NY, USA). Informed consent in adherence to the principles set forth in the Helsinki Declaration was obtained from each patient for the collection of blood samples from the donor of the lung allograft prior to implantation. We performed a retrospective analysis of prospectively banked samples. All samples were prospectively collected specifically to test the hypothesis of gene and protein expression associations with post-lung transplant outcomes. This study included 192 patients consecutively transplanted. Post-lung transplantation patients underwent pulmonary function testing in the lung transplant clinic weekly for the first 3 months. Beyond 3 months, patients were seen monthly for the first year and on alternating months for the second year. Follow-up frequency was extended to every 3 months beyond the second year after surgery.

Recipient data were prospectively collected with regards to the development of chronic lung allograft dysfunction (CLAD) as determined by the permanent drop of the forced expiratory volume in $1 \mathrm{~s}\left(\mathrm{FEV}_{1}\right)$ by $>20 \%$ from their post-transplant baseline and survival. CLAD development was monitored using routine pulmonary function tests. The interval of time from transplant to development of CLAD and survival after transplant was monitored.

\section{Donor and recipient clinical information}

Donor data were collected with regard to age, smoking history, sex, last oxygen tension/inspiratory oxygen fraction ratio prior to procurement and duration of cold ischaemic preservation.

All donors received $2 \mathrm{~g}$ methylprednisolone. Recipient data were collected with regard to the development of primary graft dysfunction in the first three post-transplant days; development of CLAD was determined by the permanent drop of the $\mathrm{FEV}_{1}$ by $>20 \%$ from their post-transplant baseline and survival. The time from transplant to development of CLAD and death was monitored.

\section{Biological samples from lung allograft}

Blood samples from the donor of the lung allograft were collected at the time of lung procurement. Blood samples were stored at $-80^{\circ} \mathrm{C}$ for subsequent analysis. All samples were batched and assayed at once. Total DNA was extracted from blood with a DNA extraction kit (Qiagen, Germantown, MD, USA), according to the manufacturer's instructions. The quality of the DNA was assessed prior to assaying. Donor 
demographics and clinical data were collected by organ procurement organisation personnel and recorded in the donor medical record.

\section{Lung allograft SP-A gene variants}

The SP-A1 and SP-A2 gene polymorphisms were assessed in a blinded fashion for donor and recipient characteristics and for clinical outcomes. The SP-A1 and SP-A2 single nucleotide polymorphism (SNPs) assessment was performed using a pyrosequencing protocol. The PCR-based restriction fragment length polymorphism genotype method for SP-A provided the basis for the pyrosequencing protocol, which is a primer-based DNA sequencing method. Pyrograms are scored by pattern-recognition software that compares the predicted SNP pattern (histogram) to the observed pattern (pyrogram) (Pyrosequencing $\mathrm{AB}$, Uppsala, Sweden). Scoring of SP-A1 $\left(6 \mathrm{~A}, 6 \mathrm{~A}^{2-20}\right)$ and SP-A2 $\left(1 \mathrm{~A}, 1 \mathrm{~A}^{0-13}\right)$ gene variants was performed, as described previously $[16,17]$.

\section{Statistical analysis}

We analysed categorical data using Chi-squared and Fisher's exact tests. We constructed stratified Cox proportional hazards models to examine associations between genotype and time to events of interest (CLAD and survival) with strata for recipient disease and with adjustment for a priori purposely selected recipient variables known to affect outcome after lung transplantation (i.e. precision variables). For time-to-death analyses, we censored follow-up time at the end of the study. For the CLAD analyses, we censored follow-up time at death and at end of study. Variants were assumed to have additive effects. There were no missing covariate data.

\begin{tabular}{|c|c|c|c|c|}
\hline \multirow[b]{2}{*}{ SP-A1 } & \multicolumn{2}{|c|}{ Variant frequency } & \multicolumn{2}{|c|}{ Genotype frequency } \\
\hline & $6 A^{2}$ & 53 (199) & $6 \mathrm{~A} 6 \mathrm{~A}^{2}$ & $5(10)$ \\
\hline & $6 A^{3}$ & $34(126)$ & $6 A 6 A^{4}$ & $0.5(1)$ \\
\hline & $6 \mathrm{~A}$ & $6(23)$ & $6 A^{2} 6 A^{2}$ & 28 (53) \\
\hline & $6 A^{4}$ & $7(28)$ & $6 A^{2} 6 A^{3}$ & $34.5(66)$ \\
\hline & & & $6 A^{2} 6 A^{4}$ & 9 (17) \\
\hline & & & $6 A^{3} 6 A^{3}$ & $11(21)$ \\
\hline & & & $6 A^{3} 6 A^{4}$ & $4(8)$ \\
\hline & & & $6 \mathrm{~A} 6 \mathrm{~A}$ & $0.5(1)$ \\
\hline & & & $6 \mathrm{~A} 6 \mathrm{~A}^{3}$ & $5(10)$ \\
\hline & & & $6 A^{4} 6 A^{4}$ & $0.5(1)$ \\
\hline & & & Blank $\#$ & $2(4)$ \\
\hline \multirow[t]{21}{*}{ SP-A2 } & $1 A^{0}$ & 52 (195) & $1 A^{0} 1 A$ & $9(18)$ \\
\hline & $1 A^{1}$ & 19 (73) & $1 A^{0} 1 A^{0}$ & $28(54)$ \\
\hline & $1 \mathrm{~A}$ & 10 (38) & $1 A^{0} 1 A^{1}$ & 20 (38) \\
\hline & $1 A^{2}$ & 9 (33) & $1 A^{0} 1 A^{2}$ & $6(12)$ \\
\hline & $1 A^{3}$ & $2(9)$ & $1 A^{0} 1 A^{3}$ & $1.5(3)$ \\
\hline & $1 A^{5}$ & $6(23)$ & $1 A^{0} 1 A^{5}$ & $7.5(14)$ \\
\hline & $1 A^{8}$ & $1(3)$ & $1 A^{1} 1 A^{5}$ & $3(6)$ \\
\hline & $1 A^{9}$ & $0.5(1)$ & $1 A^{1} 1 A^{8}$ & $0.5(1)$ \\
\hline & $1 A^{10}$ & $0.5(1)$ & $1 \mathrm{~A} 1 \mathrm{~A}$ & $0.5(1)$ \\
\hline & & & $1 \mathrm{~A} 1 \mathrm{~A}^{1}$ & $5(9)$ \\
\hline & & & $1 \mathrm{~A} 1 \mathrm{~A}^{2}$ & $2(4)$ \\
\hline & & & $1 A^{0} 1 A^{9}$ & $0.5(1)$ \\
\hline & & & $1 \mathrm{~A} 1 \mathrm{~A}^{3}$ & $1.5(3)$ \\
\hline & & & $1 A^{1} 1 A^{1}$ & $2.5(5)$ \\
\hline & & & $1 A^{1} 1 A^{2}$ & $5(10)$ \\
\hline & & & $1 \mathrm{~A} 1 \mathrm{~A}^{8}$ & $1(2)$ \\
\hline & & & $1 A^{2} 1 A^{2}$ & 1.5 (3) \\
\hline & & & $1 A^{2} 1 A^{5}$ & $0.5(1)$ \\
\hline & & & $1 A^{3} 1 A^{5}$ & $1(2)$ \\
\hline & & & $1 A^{3} 1 A^{10}$ & $0.5(1)$ \\
\hline & & & Blank $^{\#}$ & $2(4)$ \\
\hline
\end{tabular}

Data are presented as \% (n), where $n$ represents the total number of such variant or genotype in the studied patient population. $\mathrm{n}=192$. \# : lungs in which the genotype could not be determined. 
Differences were considered significant when the $\mathrm{p}$-value was $<0.05$. Continuous variables are expressed as medians and 25-75th percentile range. Statistical analysis was performed using SAS 9.2 software (SAS Institute, Cary, NC, USA).

\section{Results}

\section{Donor and recipient information}

Table 1 shows the donor lung SP-A1 and the SP-A2 variant frequencies seen in our cohort of lung transplant recipients. Supplementary table S1 shows the SPA1 and SPA2 genotype combinations. The overall characteristics of the 192 lung transplant recipients and of the donors are shown in table 2.

The overall median follow-up time was 1290 (823-1843) days. To date, 60 out of 192 patients have died, four within 30 days of the lung transplant and 56 with a median survival of 719 (274-1269) days. The 132 patients currently alive have a median follow-up of 1595 (1091-2054) days. CLAD was diagnosed in 88 patients, 38 of whom have died, with median survival of 902 (575-1422) days and 50 of whom are currently alive with a median follow-up of 1841 (1450-2296) days. Patients alive and free of CLAD are 81 with a median follow-up of 1303 (1006-1823) days. Table 2 shows the overall recipient and donor characteristics of the study cohort.

\section{Grouping of lung transplant recipients: SP-A2 variant and genotype associations}

Lung transplant recipients were grouped according to the two most frequent donor SP-A1 $\left(6 \mathrm{~A}^{2}\right.$ and $\left.6 \mathrm{~A}^{3}\right)$ and SP-A2 variants $\left(1 \mathrm{~A}^{0}\right.$ and $\left.1 \mathrm{~A}^{1}\right)$. No association with clinical outcomes was noted for the SP-A1 variants. Figure 1 shows the non-adjusted survival curves for patients grouped according to the SP-A2 variants as well as the curves conditional to 1-year survival. No association was noted for freedom from CLAD. The characteristics of the patients grouped according to the SP-A2 SNP variants for $1 \mathrm{~A}^{0}$ and $1 \mathrm{~A}^{1}$ shown in table 3 include recipient age, sex, end-stage pulmonary disease, type of transplant, cytomegalovirus (CMV) mismatch and sex mismatch. With regard to the distribution of recipient diagnoses, some differences were noted; in particular, cystic fibrosis $\left(24 \%\right.$ for variant $1 \mathrm{~A}^{0}$ versus $17 \%$ for variant $\left.1 \mathrm{~A}^{1}\right)$ and chronic obstructive pulmonary disease (COPD) (25\% for variant $1 \mathrm{~A}^{0}$ versus $34 \%$ for variant $\left.1 \mathrm{~A}^{1}\right)$, whereas interstitial lung disease and "other" were approximately half and half of each variant (table 3 ).

Figure 2 shows the non-adjusted survival curves for patients grouped according to the SP-A2 genotypes $1 \mathrm{~A}^{0} 1 \mathrm{~A}^{0}$ and $1 \mathrm{~A}^{0} 1 \mathrm{~A}^{1}$ as well as the curves conditional to 1 -year survival. The characteristics of the patient grouped according to the SP-A2 genotypes for $1 \mathrm{~A}^{0} 1 \mathrm{~A}^{0}$ and $1 \mathrm{~A}^{0} 1 \mathrm{~A}^{1}$ shown in table 4 include recipient age, sex, end-stage pulmonary disease, type of transplant, CMV mismatch and sex mismatch. With regard to the distribution of the recipient diagnoses, some differences were noted: cystic fibrosis $28 \%$ for genotype

\section{TABLE 2 Lung transplant recipient and donor characteristics}

$\begin{array}{lc}\text { Recipients } & 192 \\ \text { Male } & 90(47) \\ \text { Age years } & 57(43-62) \\ \text { Bilateral } & 141(73) \\ \text { Disease } & \\ \text { COPD } & 56(29) \\ \text { ILD } & 76(40) \\ \text { CF } & 37(19) \\ \text { PPH } & 6(3) \\ \text { Bronchiectasis } & 6(3) \\ \text { Sarcoidosis } & 7(4) \\ \text { Scleroderma } & 4(2) \\ \text { CMV mismatch } & 52(27) \\ \text { PGD-3 at } 72 \mathrm{~h} & 16(8) \\ \text { Lung donors } & \\ \text { Male } & 99(52) \\ \text { Age years } & 35(23-47) \\ \text { Last } P_{\mathrm{O}_{2}} \text { mmHg } & 457(402-506) \\ \text { Smoking } & 63(33)\end{array}$

Data are presented as $\mathrm{n}, \mathrm{n}(\%)$ or median (interquartile range). COPD: chronic obstructive pulmonary disease; ILD: interstitial lung disease; CF: cystic fibrosis; PPH: primary pulmonary hypertension; CMV: cytomegalovirus; PGD: primary graft dysfunction; $P_{\mathrm{O}_{2}}$ : oxygen tension. 

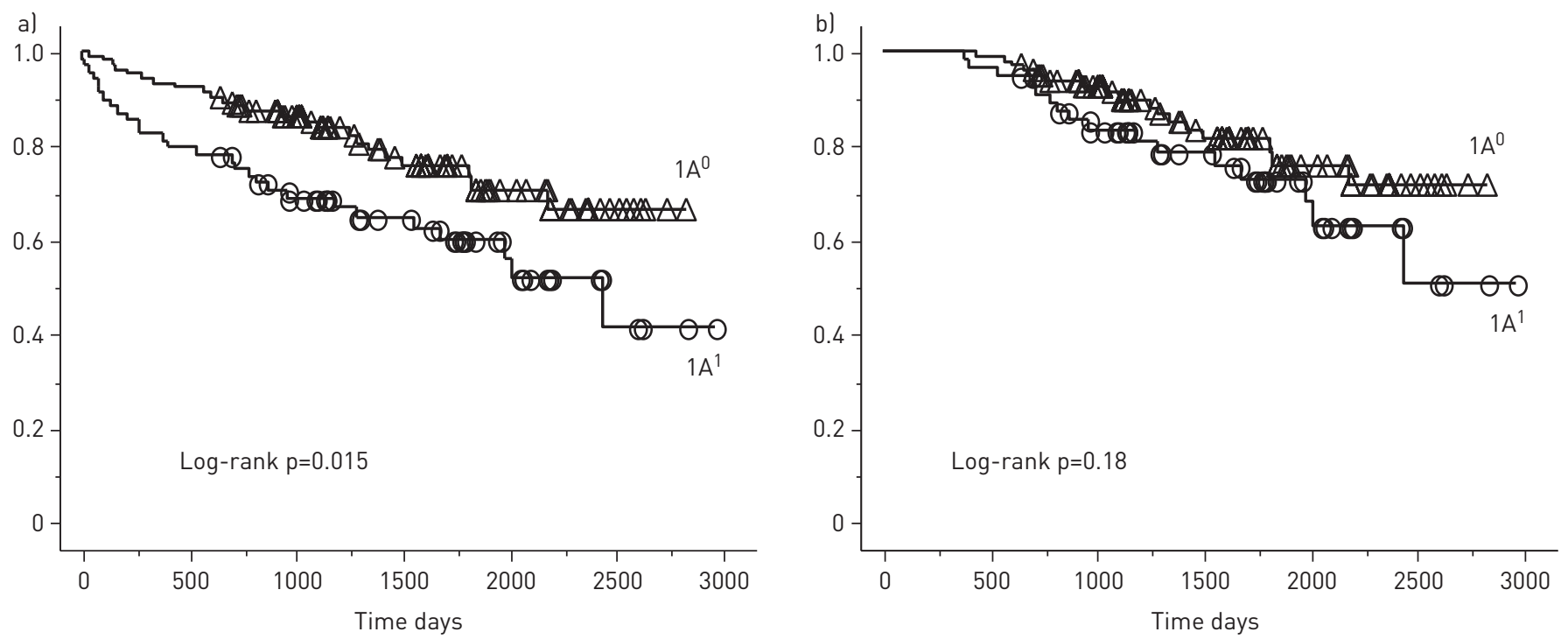

FIGURE 1 Non-adjusted lung transplant patient actual survival curves of recipients grouped according to the lung allograft donor surfactant protein (SP)-A2 polymorphic variants $1 A^{0}$ and $1 A^{1}$. A significantly greater survival during the first year post-lung transplantation was noted for recipients of donor lungs with SP-A2 variant $1 \mathrm{~A}^{1}$. Mantel-Cox log-rank test showed $\mathrm{p}=0.015$ for the overall survival analysis, although no significant difference for survival in patients that were alive at 1 year after lung transplantation. a) Survival; b) conditional 1-year survival.

$1 \mathrm{~A}^{0} 1 \mathrm{~A}^{0}$ versus $18 \%$ for variant $1 \mathrm{~A}^{0} 1 \mathrm{~A}^{1}$; COPD $24 \%$ for genotype $1 \mathrm{~A}^{0} 1 \mathrm{~A}^{0}$ versus $37 \%$ for $1 \mathrm{~A}^{0} 1 \mathrm{~A}^{1}$; and for interstitial lung disease and "other" about half and a half with each genotype (table 4).

\section{1-year survival}

Table 5 shows the 1-year survival models stratified for recipient diagnosis, with adjustment for donor polymorphic variation in $1 \mathrm{~A}^{1}$, recipient age, sex, procedure type, CMV status and sex mismatch. The data showed a significant effect in recipients with regards to the presence of donor variant $1 \mathrm{~A}^{1}(\mathrm{p}=0.02)$, age $(p=0.04)$ and bilateral lung transplant $(p=0.04)$ on the 1 -year survival. In addition, table 5 shows the 1-year survival models for the SP-A2 genotypes stratified for recipient diagnosis, with adjustment for donor polymorphic variation in $1 \mathrm{~A}^{1}$, recipient age, sex, procedure type, CMV status and sex mismatch. The SP-A2 $1 \mathrm{~A}^{0} \mathrm{~A}^{1}$ genotype was associated with a significant overall reduction in survival $(\mathrm{p}=0.02)$ in the

TABLE 3 Donor and recipient characteristics according to the donor surfactant protein (SP)-A2 variants

\begin{tabular}{lll} 
& $1^{\mathbf{0}}$ & $1^{1}$ \\
\hline Recipients & \\
Age years & $102(60)$ & $68(40)$ \\
Female & $56(43-61)$ & $57(42-63)$ \\
Bilateral transplant & $57(56)$ & $36(53)$ \\
CMV mismatch & $78(76)$ & $51(75)$ \\
Sex mismatch & $26(25)$ & $21(31)$ \\
Disease & $36(35)$ & $22(32)$ \\
CF & $24(24)$ & $12(17)$ \\
COPD & $26(25)$ & $23(34)$ \\
ILD & $39(38)$ & $25(37)$ \\
Other & $13(13)$ & $8(12)$ \\
Donors & $36(24-47)$ & $40(22-51)$ \\
Age years & 28 & 34 \\
Smoking & $468(415-504)$ & $425(393-492)$ \\
Last $P_{\mathrm{O}_{2}} \mathrm{mmHg}$ & &
\end{tabular}

Data are presented as $\mathrm{n}(\%)$, median (interquartile range) or \%. CMV: cytomegalovirus; CF: cystic fibrosis; COPD: chronic obstructive pulmonary disease; ILD: interstitial lung disease; $P_{\mathrm{O}_{2}}$ : oxygen tension. ${ }^{\#}: \mathrm{n}=170$. 

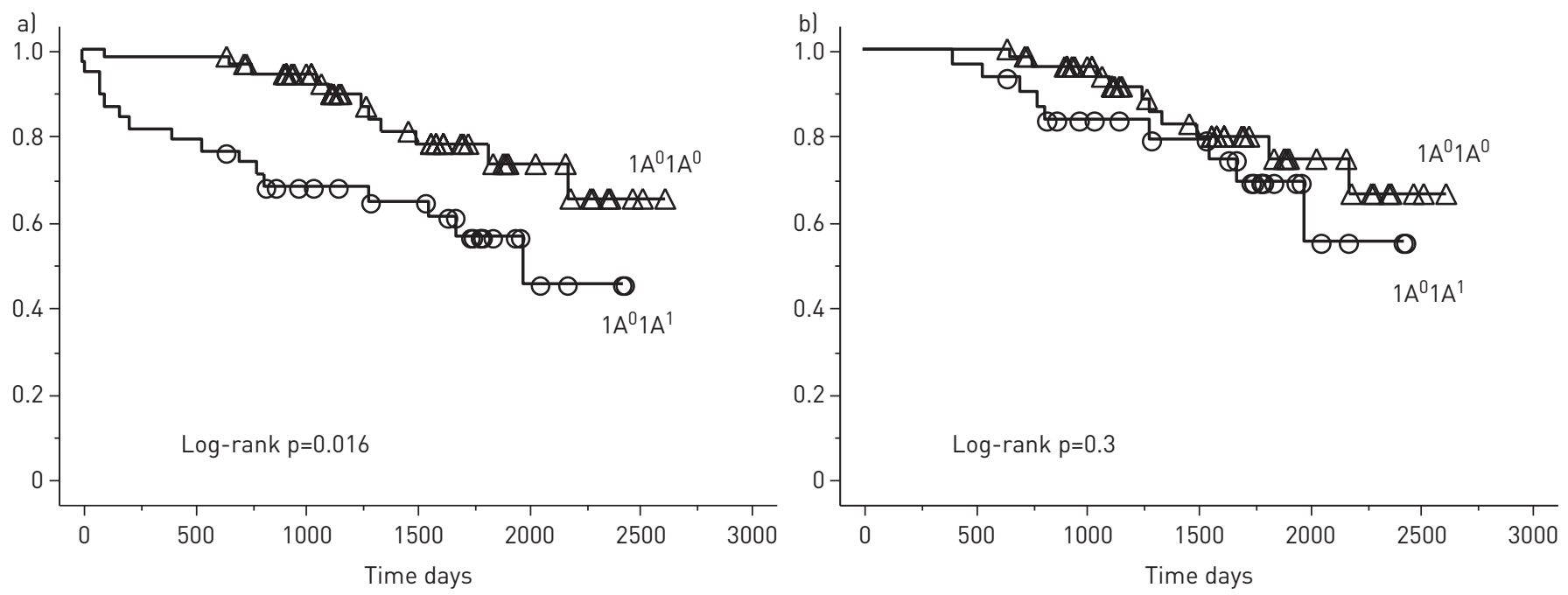

FIGURE 2 Non-adjusted lung transplant patient actual survival curves for recipients grouped according to the lung allograft donor surfactant protein (SP)-A2 polymorphic genotypes $1 \mathrm{~A}^{0} 1 \mathrm{~A}^{0}$ and $1 \mathrm{~A}^{0} 1 \mathrm{~A}^{1}$. A significant greater survival during the first year post-lung transplantation was noted for recipients of donor lungs with SP-A2 genotype $1 A^{0} 1 A^{0}$. The Mantel-Cox log-rank test showed ( $\left.p=0.016\right)$ for the overall survival, although no significant difference in patients that were alive at 1 year after lung transplantation. a) Survival; b) conditional 1-year survival.

first year. Table 6 shows the cause of death within the first year, according to the donor $1 \mathrm{~A}^{1}$ and $1 \mathrm{~A}^{0}$ variants as well as according to the donor SP-A2 genotypes $1 \mathrm{~A}^{0} 1 \mathrm{~A}^{0}$ and $1 \mathrm{~A}^{0} 1 \mathrm{~A}^{1}$.

\section{Discussion}

The role of the genetic background of the donor lung has not been sufficiently explored in relation to lung transplant recipient outcomes. This study reports novel findings with regards to the role played by SP-A gene polymorphisms in clinical outcomes post-lung transplantation. Donor lung SP-A polymorphic variants may serve as predictors of post-transplant recipient survival. The SP-A1 and SP-A2 gene polymorphisms were investigated, uncovering a significant association between the donor lung SP-A2 variants and post-lung transplant recipient survival.

We have previously reported that donor lung SP-D polymorphisms predict chronic lung allograft dysfunction, although no association to survival was reported for any of those variants [18]. Hence, the

\begin{tabular}{|c|c|c|}
\hline & $1 A^{0} 1 A^{0}$ & $1 A^{0} 1 A^{1}$ \\
\hline Recipients ${ }^{\#}$ & 54 (59) & $38(41)$ \\
\hline Age years & $54(41-61)$ & 55 (42-62) \\
\hline Female & $30(56)$ & $20(53)$ \\
\hline Bilateral transplant & 37 (69) & $30(79)$ \\
\hline CMV mismatch & $13(24)$ & $13(34)$ \\
\hline Sex mismatch & $23(43)$ & 10 (27) \\
\hline \multicolumn{3}{|l|}{ Disease } \\
\hline $\mathrm{CF}$ & $15(28)$ & $7(18)$ \\
\hline COPD & $13(24)$ & 14 (37) \\
\hline ILD & 19 (35) & $13(34)$ \\
\hline Other & $7(13)$ & $4(11)$ \\
\hline \multicolumn{3}{|l|}{ Donor } \\
\hline Age years & $37(21-47)$ & $41(30-55)$ \\
\hline Smoking & 33 & 43 \\
\hline Last $P_{\mathrm{O}_{2}}$ & $470(416-510)$ & 463 (399-507) \\
\hline
\end{tabular}

Data are presented as $\mathrm{n}(\%)$, median (interquartile range) or \%. CMV: cytomegalovirus; CF: cystic fibrosis; COPD: chronic obstructive pulmonary disease; ILD: interstitial lung disease; $P_{\mathrm{O}_{2}}$ : oxygen tension. ${ }^{\#}: \mathrm{n}=92$. 
TABLE 5 Adjusted survival models for 1-year survival stratified per recipient diagnosis

\begin{tabular}{|c|c|c|}
\hline & Hazard ratio $(95 \% \mathrm{CI})$ & p-value \\
\hline \multicolumn{3}{|c|}{ Patient grouped according to SP-A2 variant $1 A^{0}$ and $1 A^{1}$} \\
\hline Death & $2.9(1.2-6.9)$ & 0.02 \\
\hline Recipient age & $1.0(1.0-1.1)$ & 0.04 \\
\hline Female & $0.7(0.27-1.8)$ & 0.4 \\
\hline Bilateral lung transplant & $5.4(1-27.5)$ & 0.04 \\
\hline CMV mismatch & $0.8(0.3-2.2)$ & 0.7 \\
\hline Sex mismatch & $1.1(0.4-2.9)$ & 0.8 \\
\hline \multicolumn{3}{|c|}{ Patient grouped according to SP-A2 genotype $1 A^{0} 1 A^{0}$ and $1 A^{0} 1 A^{1}$} \\
\hline Death & $11.3(1.6-80.5)$ & 0.02 \\
\hline Recipient age & $1.1(1.0-1.2)$ & 0.1 \\
\hline Female & $1.1(0.3-4.5)$ & 0.9 \\
\hline Bilateral lung transplant & $2.9(0.5-15.8)$ & 0.2 \\
\hline CMV mismatch & $0.4(0.07-2.5)$ & 0.4 \\
\hline Sex mismatch & $1.1(0.2-6.2)$ & 0.9 \\
\hline
\end{tabular}

two hydrophilic surfactant proteins SP-D and SP-A may have a distinct impact on the overall innate and adaptive response to pathogens.

The human SP-A locus consists of two functional genes, sftpal and sftpa2, encoding SP-A1 and SP-A2, respectively. Each gene has been identified with several polymorphisms within the coding region, which may or may not be subject to amino acid substitutions, SP-A1 $\left(6 \mathrm{~A}, 6 \mathrm{~A}^{2-20}\right)$, and SP-A2 $\left(1 \mathrm{~A}, 1 \mathrm{~A}^{0-13}\right)[12$, 16]. Associations of SP-A1 and SP-A2 variants have been shown for several pulmonary diseases $[9,10]$ and mutations in these genes are found in patients with interstitial lung disease and lung cancer. Despite such frequency, their pathologic mechanism is poorly understood. Gene polymorphisms of SP-A1 and SP-A2 may be responsible for both quantitative and qualitative differences in levels of protein synthesis, variations in protein functionality, or an altered ratio between the two proteins SP-A1 and SP-A2 [19-23]. Hence, within the context of organ specific innate immunity, a compromised surfactant proteomic composition may largely contribute to a deficiency in first-line responses to various insults.

Recent animal studies have shown that not only do SP-A1 and SP-A2 variants distinctively affect the alveolar macrophage miRNome [24], but, most relevantly, they differentially affect lung function and survival after infection $[25,26]$. It is therefore conceivable that SP-A gene variants may contribute to the complex aetiologic pathogenesis of lung allograft dysfunction. This retrospective study, despite having a potential bias from uneven distribution of patient characteristics, which was taken in account in the adjusted statistical analysis, documents this association for the first time showing a significantly greater risk of death within the first year post-lung transplant for recipients of donor lungs with SP-A2 variant $1 \mathrm{~A}^{1}$ and genotype $1 \mathrm{~A}^{0} 1 \mathrm{~A}^{1}$ compared to others (figure 1 and table 5). This appears to be due to a greater incidence of death from infection (table 6). Interestingly, Dominic et al. [27] demonstrated that homozygosity of the SP-A2 variant, $1 \mathrm{~A}^{1}$, was associated with an increased risk of meningococcal disease, suggesting a recessive effect of this variant. The carriage of another SP-A2 variant, $1 \mathrm{~A}^{5}$, was significantly associated with a reduced risk of infection, suggesting a dominant effect of this variant. Variants $1 \mathrm{~A}^{1}$ and $1 \mathrm{~A}^{5}$ are identical at the codons that encode amino acids 9 and 140, but they differ at amino acids 91 and

\begin{tabular}{|c|c|c|c|c|}
\hline & $1 A^{1}$ & $1 A^{0}-1 A^{1}$ & $1 A^{0}$ & $1 A^{0} 1 A^{0}$ \\
\hline Subjects & 12 & 7 & 7 & 1 \\
\hline Pneumonia & 8 & 5 & 4 & 0 \\
\hline Multi-organ failure & 2 & 2 & 1 & 0 \\
\hline CLAD & 1 & 0 & 1 & 0 \\
\hline Pulmonary embolism & 1 & 0 & 1 & 1 \\
\hline
\end{tabular}

Data are presented as n. CLAD: chronic lung allograft dysfunction. 
223 [27]. The change in amino acid 223 between these two variants is significant. Variants $1 \mathrm{~A}^{5}$ and $1 \mathrm{~A}^{0}$ that were associated with reduced infection risk $\left(1 \mathrm{~A}^{5}\right)$ [27] and better survival $\left(1 \mathrm{~A}^{0}\right)$ in the present study and in a recent mouse study [26] have the same amino acid, namely a glutamine. This charged amino acid may contribute to a better outcome.

Low levels of SP-A mRNA measured in the lung allograft just prior to implantation appeared to be a negative predictor with respect to post-transplant survival [14]. An association between donor lung SP-A mRNA expression levels and SP-A2 genotype has been previously observed [14]. In particular, the SP-A2 genotype $1 \mathrm{~A}^{0} \mathrm{~A}^{0}$ had greater levels of SP-A mRNA expression in the allograft prior to implantation [14]. Lung donors are treated with very high levels of steroids prior to organ procurement. We recently reported a significant pharmacogenetic relationship between SP-A2 variants and methylprednisolone. Precision cut lung slices from organs with SP-A2 variant $1 \mathrm{~A}^{0}$ and genotype $1 \mathrm{~A}^{0} 1 \mathrm{~A}^{0}$ showed a significantly greater protein expression when treated with methylprednisolone [15]. These observations are consistent with the present results, where recipients from donors with $1 \mathrm{~A}^{0}$ variant and $1 \mathrm{~A}^{0} 1 \mathrm{~A}^{0}$ genotype exhibited greater survival, indicating that the total SP-A levels determined by donor lung genotype may play a role in post-transplant recipient survival. Interestingly, the survival advantage identified in this study was observed within the first year, during which recipient immunosuppressive regimes include the greatest levels of steroids.

The lungs, like the intestines, suffer the disadvantage of a continuous exposure to the environment compared to other solid organs, thus they rely on a more active organ-specific innate immunity for first-line protection against ongoing external pathogens [28-31]. Interactions between innate and adaptive immune responses in these organs in the setting of transplantation are probably a major contributor to the increased graft dysfunction that is seen. It is conceivable that the capability of the lung allograft to withstand the various transplant related insults is driven by its genetic background, and especially that of donor innate immunity. The innate immune molecules, SP-A1 and SP-A2, are subject to differential and complex regulation as shown in vitro and in fetal lung explants [32-35].

In conclusion, donor lung SP-A2 gene polymorphisms are associated with post-transplant recipient survival. Further studies are needed to explore the different roles of SP-D and SP-A polymorphisms within the innate and adaptive immune response post-lung transplantation. This study was not designed for a detailed assessment of confounding factors or interaction effects, nevertheless the interesting findings reported significantly add weight to further hypothesis generation regarding the potential impact of genetic polymorphisms for key proteins in the donor lung influencing post-lung transplant outcome(s). In fact our findings suggest a constitutive role of the donor innate immunity towards lung transplant recipient outcome.

Conflict of interest: F. D'Ovidio reports grants from NIH-NHLBI, during the conduct of the study. J. Floros has nothing to disclose. B. Aramini has nothing to disclose. D. Lederer has nothing to disclose. S.L. DiAngelo has nothing to disclose. S. Arcasoy has nothing to disclose. J.R. Sonett has nothing to disclose. H. Robbins has nothing to disclose. L. Shah has nothing to disclose. J. Costa has nothing to disclose. A. Urso has nothing to disclose.

Support statement: This work was supported by the National Institutes of Health, NHLBI, R21HL092478-01A2; HL34788. Funding information for this article has been deposited with the Crossref Funder Registry.

\section{References}

1 Hills BA. Surface-active phospholipid: a Pandora's box of clinical applications. Part II. Barrier and lubricating properties. Intern Med J 2002; 32: 242-251.

2 Goerke J. Pulmonary surfactant: functions and molecular composition. Biochim Biophys Acta 1998; 1408: 79-89.

3 Holmskov U, Thiel S, Jensenius JC. Collectins and ficolins: humoral lectins of the innate immune defense. Annu Rev Immunol 2003; 21: 547-578.

4 Wright JR, Borron P, Brinker KG, et al. Surfactant protein A: regulation of innate and adaptive immune responses in lung inflammation. Am J Respir Cell Mol Biol 2001; 24: 513-517.

5 McCormack FX, Whitsett JA. The pulmonary collectins SP-A and SP-D, orchestrate innate immunity in the lung. J Clin Invest 2002; 109: 707-712.

6 Crouch E, Hartshorn K, Ofek I. Collectins and pulmonary innate immunity. Immunol Rev 2000; 173: 52-65.

7 Phelps DS. Surfactant regulation of host defense function in the lung: a question of balance. Pediatr Pathol Mol Med 2001; 20: 269-292.

8 Floros J, Phelps DS. Pulmonary surfactant protein A; structure, expression and its role in innate host defense. In: Nakos G, Lekka M, eds. Surfactant - Update of Intensive Care Medicine, Vol. 6. Ioannina, Greece, University of Ioannina, 2002; pp. 87-102.

9 Floros J, Thomas NJ. Genetic variations of surfactant proteins and lung injury. In: G Nakos, A Papathanasiou, eds. Surfactant in Pathogenesis and Treatment of Lung Disease. Kerala, Research Signpost, 2009; pp. 25-48.

10 Silveyra P, Floros J. Genetic variant associations of human SP-A and SP-D with acute and chronic lung injury. Front Biosci 2012; 17: 407-429.

11 Karinch AM, Floros J. 5' splicing and allelic variants of the human pulmonary surfactant protein A genes. Am J Respir Cell and Mol Biol 1995; 12: 77-88. 
12 Floros J, Hoover RR. Genetics of the hydrophilic surfactant proteins A and D. Biochim Biophys Acta 1998; 1408: 312-322.

13 Khubchandani KR, Goss KL, Engelhardt JF, et al. In situ hybridization of SP-A mRNA in adult human conducting airways. Pediatr Pathol Mol Med 2001; 20: 349-366.

14 D’Ovidio F, Kaneda H, Chaparro C, et al. Pilot study exploring lung allograft surfactant protein a (SP-A) expression in association with lung transplant outcome. Am J Transplant 2013; 13: 2722-2729.

15 Aramini B, Geraghty P, Lederer D, et al. Surfactant protein A and D polymorphisms and methylprednisolone pharmacogenetics in donor lungs. J Thorac Cardiovasc Surg 2019; 157: 2109-2117.

16 DiAngelo S, Lin Z, Wang G, et al. Novel, non-radioactive, simple and multiplex PCR-cRFLP methods for genotyping human SP-A and SP-D marker alleles. Dis Markers 1999; 15: 269-281.

17 Pavlovic J, Papagaroufalis C, Xanthou M, et al. Genetic variants of surfactant proteins A, B, C, and D in bronchopulmonary dysplasia. Dis Markers 2006; 22: 277-291

18 Aramini B, Kim C, Diangelo S, et al. Donor surfactant protein D (SP-D) polymorphisms are associated with lung transplant outcome. Am J Transplant 2013; 13: 2130-2136.

19 Wang G, Phelps DS, Umstead TM, et al. Human SP-A protein variants derived from one or both genes stimulate TNF- $\alpha$ production in the THP-1 cell line. Am J Physiol Lung Cell Mol Physiol 2000; 278: L946-L954.

20 Wang G, Umstead TM, Phelps DS, et al. The effect of ozone exposure on the ability of human surfactant protein A variants to stimulate cytokine production. Environ Health Perspect 2002; 110: 79-84.

21 Mikerov AN, Umstead TM, Gan X, et al. Impact of ozone exposure on the phagocytic activity of human surfactant protein A (SP-A) and SP-A variants. Am J Physiol Lung Cell Mol Physiol 2008; 294: L121-L130.

22 Mikerov AN, Wang G, Umstead TM, et al. Surfactant protein A2 (SP-A2) variants expressed in CHO cells stimulate phagocytosis of Pseudomonas aeruginosa more than do SP-A1 variants. Infect Immun 2007; 75: 1403-1412.

23 Tagaram HRS, Wang G, Umstead TM, et al. Characterization of a human surfactant protein A1 (SP-A1) gene-specific antibody; SP-A1 content variation among individuals of varying age and pulmonary health. Am J Physiol Lung Cell Mol Physiol 2007; 292: 1052-1063.

24 Noutsios GT, Thorenoor N, Zhang X, et al. SP-A2 contributes to miRNA-mediated sex differences in response to oxidative stress: pro-inflammatory, anti-apoptotic, and anti-oxidant pathways are involved. Biol Sex Differ 2017; 8: 37 .

25 Thorenoor N, Zhang X, Umstead TM, et al. Differential effects of innate immune variants of surfactant protein-A1 (SFTPA1) and SP-A2 (SFTPA2) in airway function after Klebsiella pneumoniae infection and sex differences. Respir Res 2018; 19: 23.

26 Thorenoor N, Umstead TM, Zhang X, et al. Survival of surfactant protein-A1 and SP-A2 transgenic mice after Klebsiella pneumoniae infection, exhibits sex-, gene-, and variant specific differences; treatment with surfactant protein improves survival. Front Immunol 2018; 9: 2402.

27 Dominic LJ, Cole J, Naylor SC, et al. Genetic polymorphism of the binding domain of surfactant protein-a2 increases susceptibility to meningococcal disease. Clin Infect Dis 2006; 43: 1426-1433.

28 Ghanekar A, Grant D. Small bowel transplantation. Curr Opin Crit Care 2001; 7: 133-137.

29 Brown RS, Rush SH, Rosen HR, et al. Liver and intestine transplantation. Am J Transplant 2004; 4: Suppl. S9, 81-92.

30 Wynn JJ, Distant DA, Pirsch JD, et al. Kidney and pancreas transplantation. Am J Transplant 2004; 4: Suppl. S9, 72-80.

31 Pierson RN, Barr ML, McCullough KP, et al. Thoracic organ transplantation. Am J Transplant 2004; 4: Suppl. S9, 93-105.

32 Kumar AR, Snyder JM. Differential regulation of SP-A1 and SP-A2 genes by cAMP, glucocorticoids, and insulin. Am J Physiol 1998; 274: L177-L185.

33 Alcorn JL, Islam KN, Young PP, et al. Glucocorticoid inhibition of SP-A gene expression in lung type II cells is mediated via the TTF-1-binding element. Am J Physiol Lung Cell Mol Physiol 2004; 286: L767-L776.

34 Thomas NJ, DiAngelo SL, Willson DF, et al. Surfactant protein A genetic variants in children hospitalized with respiratory syncytial virus disease. Crit Care Med 2004; 32: A115.

35 Wang G, Guo X, Floros J. Human SP-A-3'-UTR variants mediate differential gene expression in basal levels and in response to dexamethasone. Am J Physiol Lung Cell Mol Physiol 2003; 284: L738-L748. 